\title{
DESENHO TÉCNICO: PADRÕES DE REPRESENTAÇÃO GRÁFICA PARA PRODUTOS DO VESTUÁRIO.
}

\author{
PULS, Lourdes Maria ${ }^{1}$
}

\section{RESUMO}

Este trabalho sintetiza a pesquisa "Desenho Técnico: padrões de representação para o projeto de produtos do vestuário". Que teve como objetivo propor procedimentos de construção de desenhos técnicos de produto do vestuário, a partir do desenho estético. Levantar as competências essenciais à representação gráfica para desenvolvimento de projeto de produto, através de bibliografias. Identificar os diferentes produtos de vestuário e suas especificidades e finalmente propor a padronização de desenho técnico para representação gráfica de produtos de vestuário.

Palavra-chave: Desenho técnico, vestuário, produto de moda.

\section{INTRODUÇÃO}

Nesta pesquisa buscou-se ressaltar a importância do conhecimento sobre processos de representação gráfica técnica ou planificada, através do desenho, dos produtos do vestuário. No estudo, procurou-se desenvolver novos procedimentos e padrões relacionados com a prática de construção de representação gráfica técnica bidimensional dos produtos do vestuário masculino, feminino e infantil.

\footnotetext{
${ }^{1}$ Mestre em Gestão de Design pela Universidade Federal de Santa Catarina - UFSC Professora de Desenho de Moda na Universidade do Estado de Santa Catarina C2Imp@udesc.br
}

DAPesquisa, Florianópolis, v.2, n.4, p. 408-422, 2007. 
A aplicação de padrões na construção de desenhos técnicos e soluções nos procedimentos de construção de representação gráfica permitiu um melhor desempenho nas atividades, por parte dos alunos, no que diz respeito à elaboração dos desenhos, a produtividade, qualidade e variações na criação de modelos, bem como na otimização dos trabalhos na modelagem, corte, produção e confecção das peças de roupas.

É pelo domínio de uma linguagem gráfica e visual, que o futuro desenhista de moda mostra as formas estéticas com movimentos, cores e texturas, pelo croqui, que no contexto do vestuário é o desenho artístico do modelo da roupa. Porém, obrigatoriamente deve vir acompanhado de seu complemento, ou seja, do desenho técnico que representa as formas funcionais (diagramadas ou planificadas), onde se visualiza todas as especificações do produto com os detalhes e rigor técnico exigidos em outras áreas de conhecimento.

Para o educador, o interesse em aprofundar este assunto colocou-se em refletir sobre esta problemática, que enriquece o método de ensino e de aprendizagem. A preocupação com os estudantes foi para que fossem autônomos em suas buscas, preparando-os para que sejam profissionais com sólida formação. Portanto o estudo de procedimentos didáticos e pedagógicos, do desenho técnico, teve a intenção de motivar o uso de padrões na construção da representação técnica. Assim, ofereceuse aos alunos do curso de Moda da UDESC, um método que facilitou a interpretação do modelo da peça de roupa. A aquisição da competência relativa aos materiais e técnicas possibilitou a transformação de um modelo em um protótipo, conseqüentemente, pronto para produção em escala industrial.

\section{METODOLOGIA}

De acordo com Lakatos (2001:80), o conhecimento científico deve ser obtido através da experiência e não apenas pela razão, trata-se de um saber ordenado logicamente, formado em sistemas de idéias (teorias) e não deve ser definitivo.

Sendo assim, o método utilizado na presente pesquisa baseou-se numa abordagem sistêmica e gradual, permitindo desta forma a absorção pouco a pouco da compreensão sobre a construção de padrões de representação gráfica técnica e sua aplicabilidade nas disciplinas de desenho técnico de moda, através de estudo teórico e prático. Assim executou-se os seguintes passos metodológicos: $1^{\circ}$ Revisão Bibliográfica: Nesta etapa buscou-se levantar na pesquisa bibliográfica, o 
referencial teórico por meio de fontes bibliográficas e documentais disponível que contribuísse para as etapas seguintes do processo metodológico. $2^{\circ}$ Procedimentos: esta etapa consistiu na pesquisa prática realizada com alunos de desenho de moda da Universidade do Estado de Santa Catarina - UDESC - onde se desenvolveu e trabalhou-se diferentes procedimentos de padronização na construção do desenho técnico. $3^{\circ}$ - Análise dos dados levantados. Resultados obtidos e considerações finais. $4^{\circ}$ - Referências Bibliográficas.

O que precisamente buscou-se pesquisar além das reflexões feitas sobre desenho técnico, desenho, expressividade e criatividade, foram novas possibilidades e soluções para a construção do desenho técnico e para criação de moda. Portanto, precisou-se primeiramente trabalhar a figura humana planificada com medidas específicas para a modelagem, bem como trabalhar tipos e espessuras de linhas, cotas estabelecendo-se assim as padronizações. Com esta aprendizagem metodológica, o aluno conseguiu fazer um elo de ligação entre o desenho da criação, desenho técnico e a modelagem.

Os preceitos da metodologia cientifica orientou a montagem estrutural desta pesquisa, o que possibilitou obter-se os resultados que serão apresentados a seguir:

\title{
PROCEDIMENTOS E RESULTADOS:
}

\begin{abstract}
O profissional da área da moda seria completamente ineficaz sem um domínio preciso da representaçao gráfica, pois a falta da mesma resultaria no fracasso para a transmissão dos projetos desenvolvidos. Apontam que a importância da linguagem gráfica pode ser observada ao compará-la com a linguagem verbal, visto que seria extremamente dificil uma pessoa ter a imagem precisa do objeto em sua mente descrito somente com palavras. Provalvelmente, o indivíduo teria necessidade de se dispor de um lápis e papel para auxiliá-lo na construção de um esboço, oferecendo com isso uma forma mais eficaz de mostrar seus pensamentos (French \&Vierck, 1999).
\end{abstract}

Esta parte do trabalho versa sobre a pesquisa prática que se realizou com alunos da disciplina Desenho Técnico do Curso de Moda da UDESC. Aqui se apresenta algum procedimento utilizado para a pesquisa e seus resultados. Portanto, para que os alunos, futuros desenhistas de moda agentes desta ação, conseguissem construir a representação gráfica técnica, pelo desenho, utilizando a padronização, estabeleceu-se alguns critérios. Um deles é que as linhas dos 
desenhos devem ser legíveis, apresentar contrastes uma das outras para uma melhor percepção do desenho. Como se pode ver na figura $n^{\circ} 01$. Para sua elaboração seguiu-se, em alguns casos, a norma já estabelecida pela ABNT (Associação Brasileira de Normas Técnicas), específicas para a área da moda, e em outras foi utilizado padrões pesquisados. A importância da representatividade gráfica se apresenta nas palavras de Suono, Silva e Paschoarelli (2006), que afirmam que em função de certos princípios de representação gráfica universal em determinadas áreas, ela acaba se tornando uma linguagem extremamente importante de projetos entre os designers e aqueles que têm o papel de executar os processos pertinentes para a produção do produto.

\section{5- Escalas usualmente adotadas}

A escala de um desenho é a relação da dimensão de um objeto ou elemento representada num desenho para a dimensão real deste objeto ou elemento.

O desenho pode ser realizado em três tipos de escala:

- escala natural: representação do objeto em sua verdadeira grandeza (1:1)

- escala de ampliação: representação do objeto maior que sua verdadeira

grandeza (X:1), geralmente utiliza-se essa escala em desenhos de detalhes de

peças, que para uma melhor compreensão são desenhados separadamente e em tamanho maior.

- escala de redução: representação do objeto menor que sua verdadeira grandeza

(1: X), utilizado na maioria dos desenhos de produtos do vestuário, sendo mais

utilizadas as escalas 1:5e 1:10

A escala escolhida para a representação gráfica do produto de vestuário deve ser coerente com a complexidade do mesmo. Para representar um desenho com um número elevado de informações é aconselhável a utilização da escala 1:5, com desenhos de detalhes em 1:2. Se a peça for pequena, pode-se optar pela escala 1:2 em todo o desenho, ou ainda escolher uma escala de ampliação. A escala selecionada deve possibilitar uma leitura clara e rápida da informação que deve ser decodificada. No desenvolvimento de produtos do vestuário as escalas usualmente adotadas são as escalas de ampliação e redução.

6- Tipos e espessuras de linhas empregadas

\begin{tabular}{|c|c|c|}
\hline Linha & Denominação & Aplicação Geral \\
\hline- & Contínua larga & Contornos \\
\hline & Contínua estreita & $\begin{array}{l}\text { Linhas de cota, linhas } \\
\text { auxiliares, linhas de } \\
\text { chamada e texturas }\end{array}$ \\
\hline & Contínua estreita a mão livre & $\begin{array}{l}\text { Limite de vistas ou } \\
\text { cortes parciais }\end{array}$ \\
\hline---------- & Tracejada estreita & Pespontos \\
\hline$------\cdot$ & Tracejada larga & Pespontos largos \\
\hline$-\cdots-\cdots-\cdots$ & Traço e ponto estreita & $\begin{array}{l}\text { Linhas de centro e } \\
\text { linhas de simetria }\end{array}$ \\
\hline$-\cdots-\cdots-\cdots-\cdots-\cdots-\cdot$ & Traço dois pontos estreita & $\begin{array}{l}\text { Contornos de peças } \\
\text { adjacentes e posição } \\
\text { limite de peças móveis. }\end{array}$ \\
\hline & Pontilhada estreita & Contornos não visíveis \\
\hline
\end{tabular}

Figura $n^{\circ} 01$ 
Como a grande maioria dos desenhos técnicos são construídos utilizando-se medidas de proporção da figura humana, construiu-se a figura humana planificada como mostra a figura $n^{\circ} 02$, aqui mostra-se a figura de frente, mas também foi construída a figura de costa e lateral, como pode-se verificar nas imagens xerocadas, anexadas nesta pesquisa. A figura planificada é utilizada como suporte para os desenhos técnicos. Na construção da figura humana planificada utilizou-se medidas já existentes na ABNT para a área do vestuário, e outras medidas utilizadas para a modelagem das roupas.

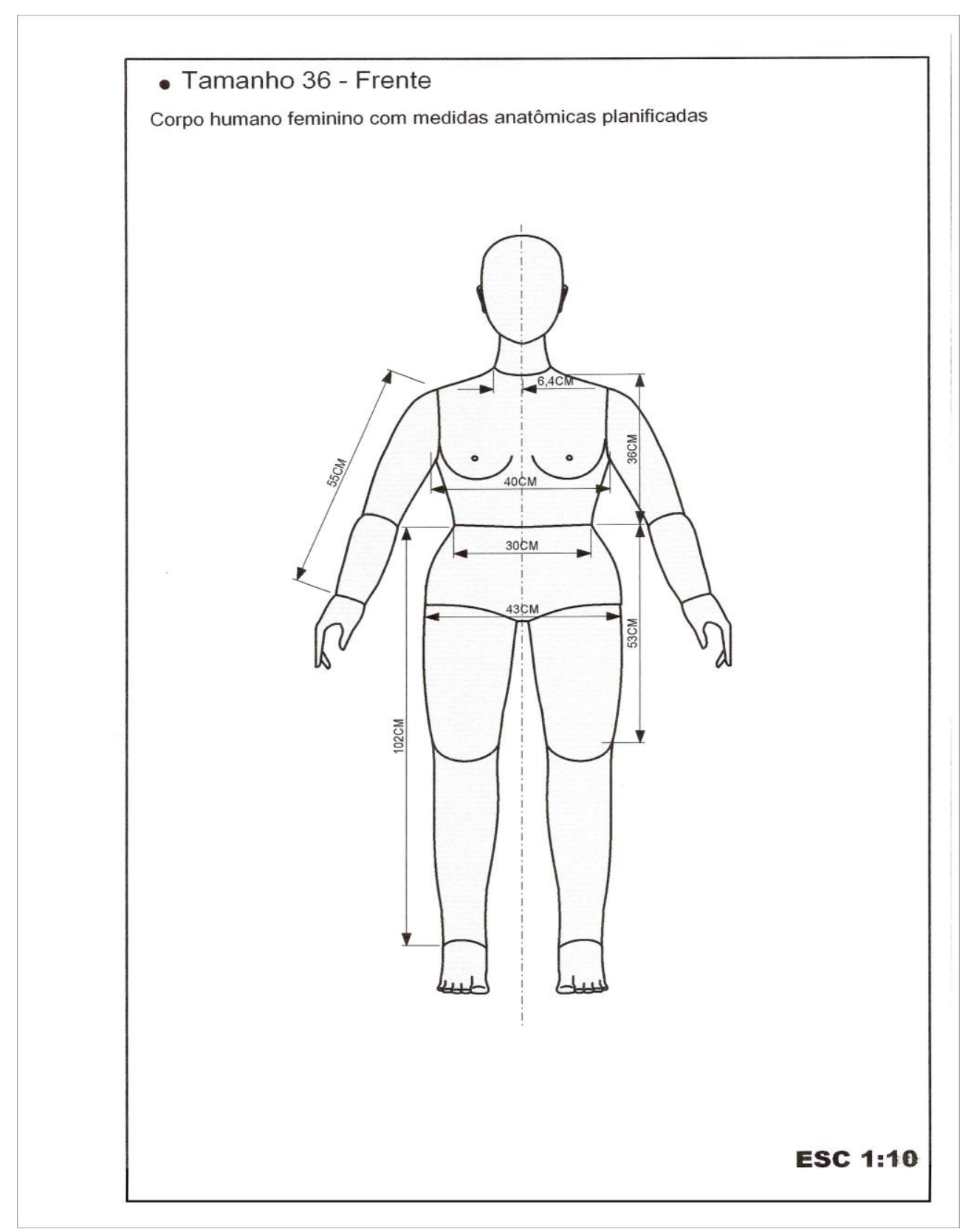

FIGURA Nº2 
As figuras masculinas e infantis foram desenhadas utilizando-se medidas da proporção da figura humana, porém também planificada, como se pode ver na figura $n^{\circ} 03$ e figura $n^{\circ} 04$. Dessa maneira o aluno conseguiu visualizar a figura sem volume, já que os desenhos técnicos das peças de roupa são desenhos planos e diagramados mostrando a peça do vestuário como se estivesse apoiada em uma superfície plana.

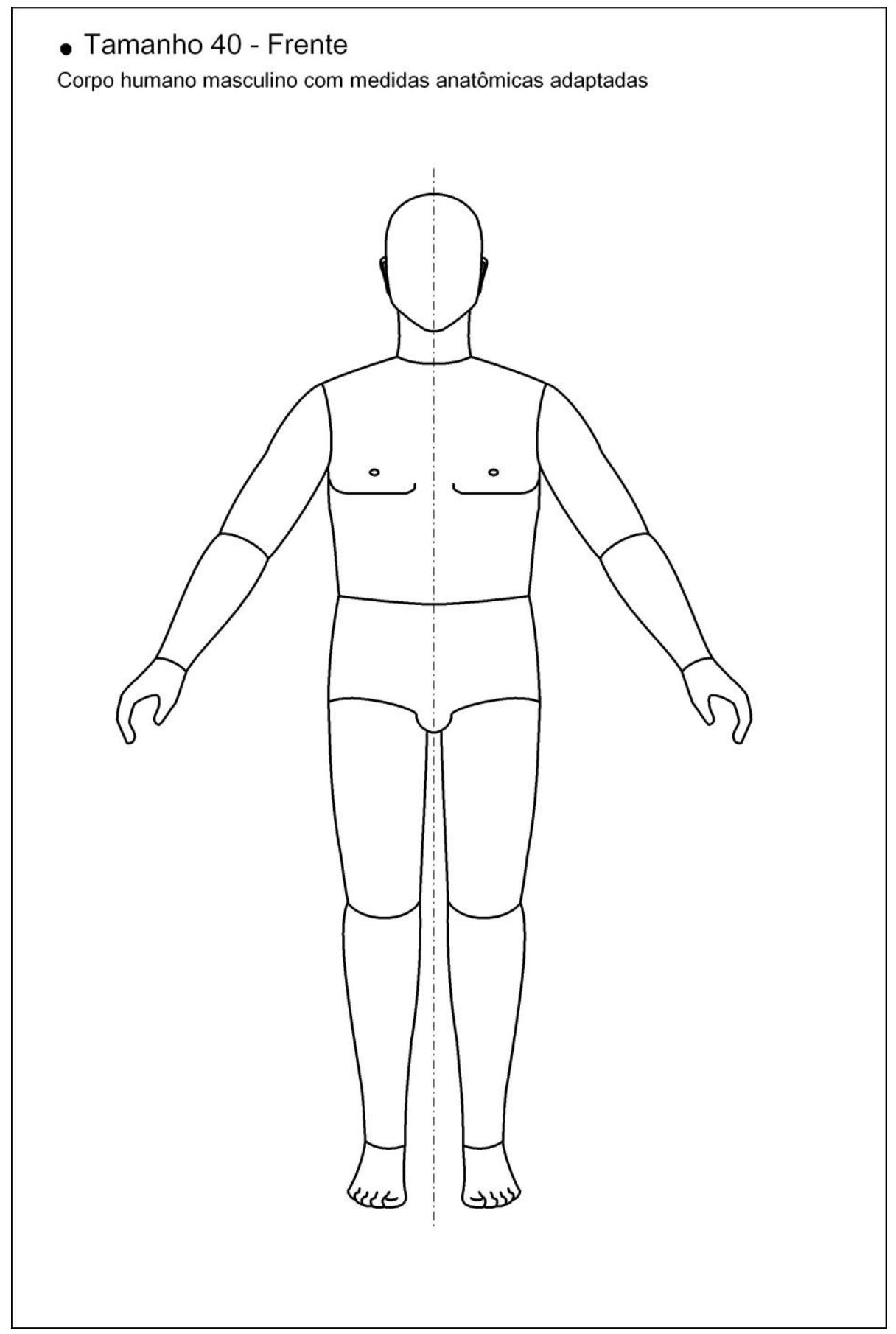

FIGURA Nº3 
- Tamanho 08 - Frente

Corpo humano infantil com medidas anatômicas planificadas

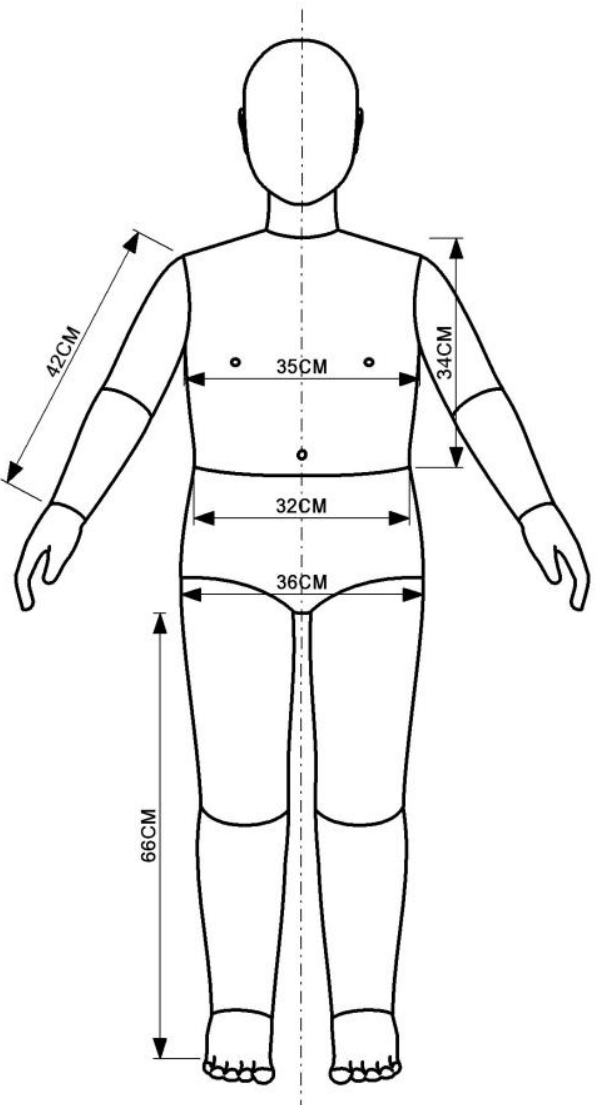

FIGURA N ${ }^{\circ} 04$

Constatou-se durante a pesquisa, que uma das dificuldades do aluno era visualizar as alturas específicas de cada peça de roupa em relação ao corpo para representa-las graficamente. Assim, utilizando-se a figura humana planificada, elaborou-se linhas limítrofes de todas as peças desde calças e vestidos, até limites 
de mangas curtas e longas. Dessa forma, a utilização do desenho técnico explicitando cortes, modelagem e execução, é completo e detalhado, com descrição da forma e do tamanho de cada peça. Para esta construção gráfica, foi utilizada medida de várias peças de roupa e transferidas para a figura planificada. Para esta transferência os pesquisadores preocuparam-se em aplicar a padronização somente quando não existiam normas já consagradas da ABNT, o resultado pode ser visto na figura $n^{\circ} 5$.

- Linhas de recortes e limites das roupas

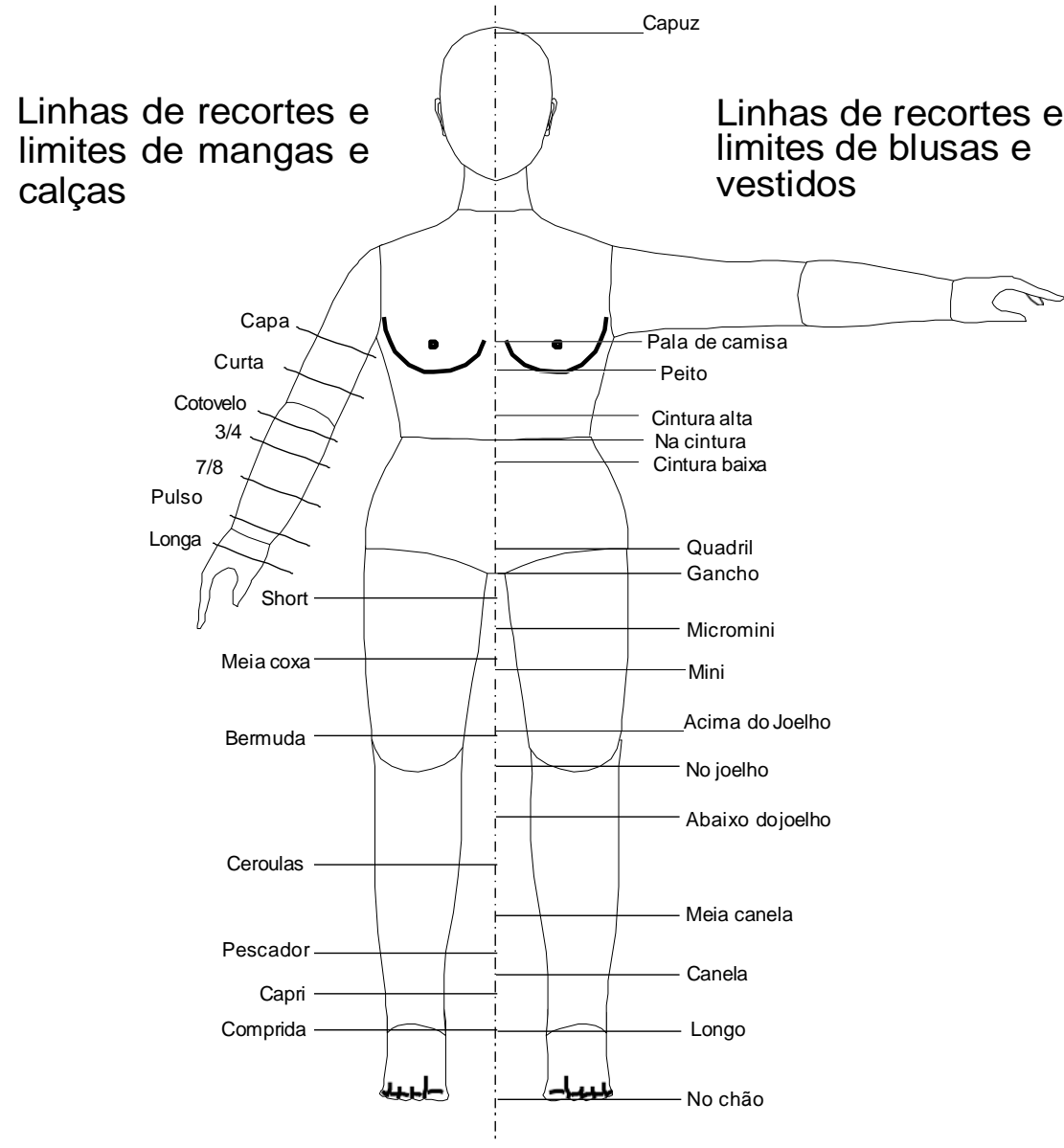


Com os suportes já elaborados, iniciou-se a aplicação dos padrões de construção na representação gráfica de peças do vestuário. Partiu-se do ensino e aprendizagem da simetria, utilização dos suportes, padrões, linhas e cotas, nesse caso, quando tivesse o protótipo pronto. Representou-se graficamente o passo a passo de várias peças, como se pode ver no exemplo da figura ${ }^{\circ} 06$ no modelo de uma jaqueta de frente, e de costas figura $n^{\circ} 07$. Em ambos os casos utilizou-se 0 suporte da figura humana planificada, e como havia o protótipo pronto, trabalhou-se com as medidas de cotagem.

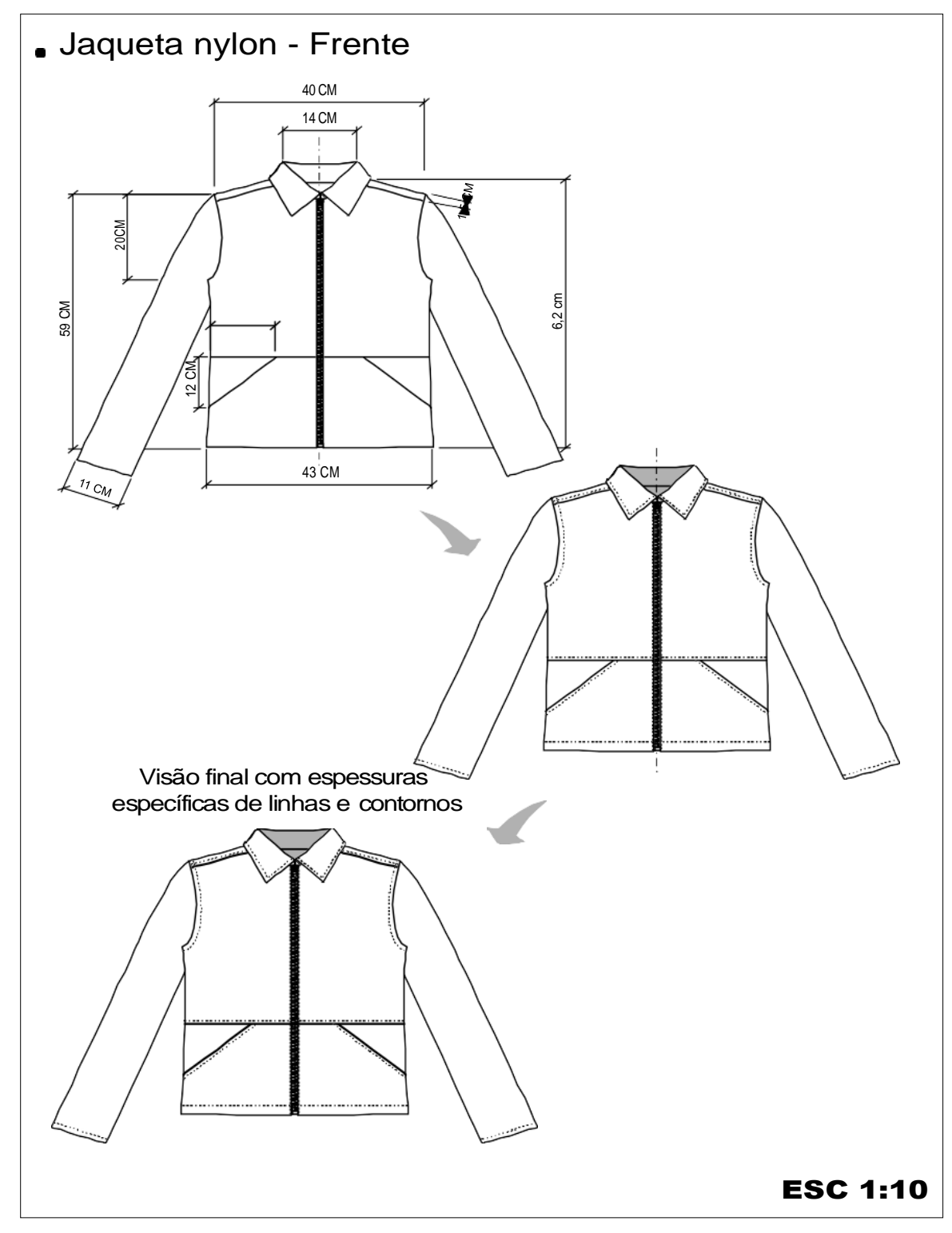

FIGURA $N^{\circ} 06$

DAPesquisa, Florianópolis, v.2, n.4, p. 408-422, 2007. 


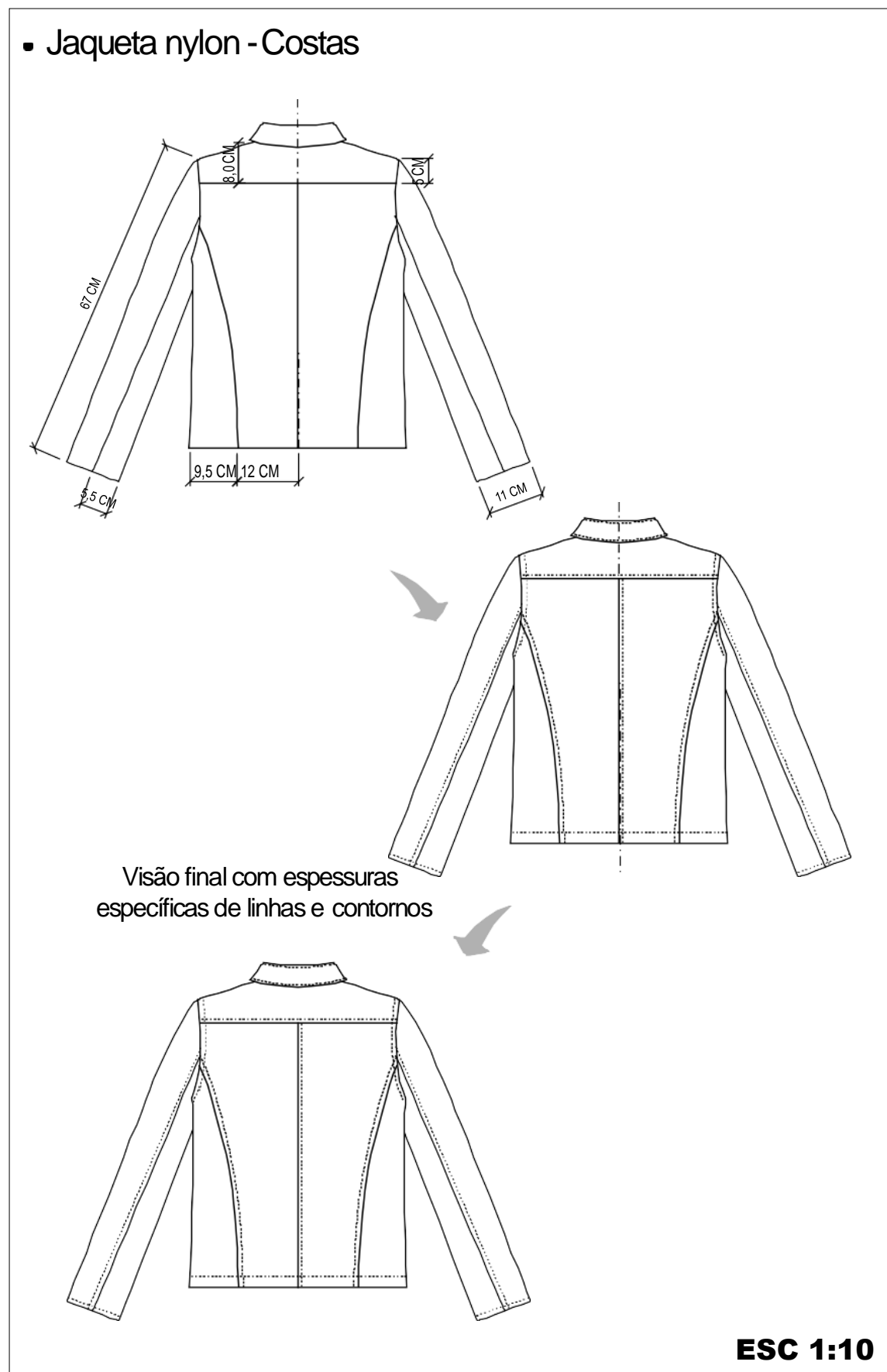

FIGURA N ${ }^{\circ} 07$

No caso específico do uso das cotas, foi tirada a medida da peça de roupa pronta (protótipos). As medidas transformadas em escalas 1:10 foram utilizadas para a construção do desenho da peça. Na figura $n^{\circ} 08$ visualiza-se o desenho da figura humana masculina planificada sendo utilizada como suporte para o desenho de uma calça jeans, peça de roupa do vestuário masculino.

DAPesquisa, Florianópolis, v.2, n.4, p. 408-422, 2007. 


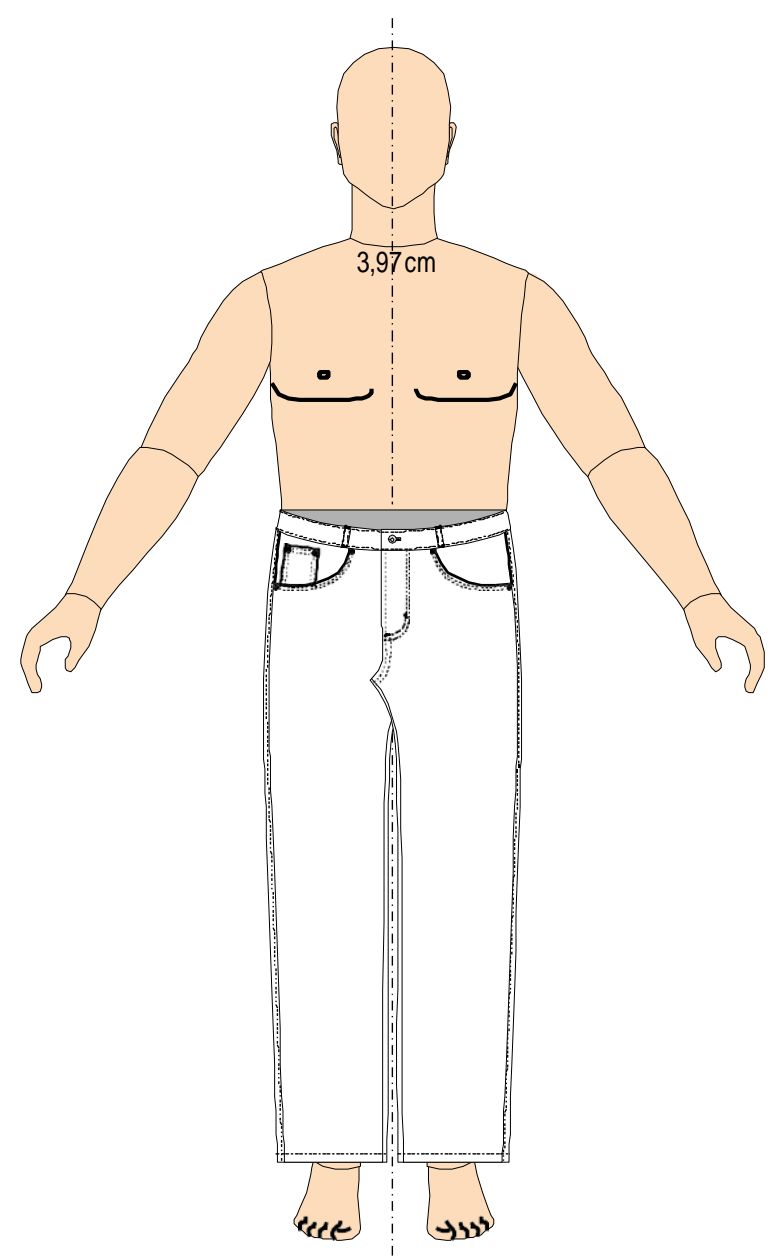

FIGURA Nº8

Muitos aspectos relacionados à transmissão de uma boa informação estão presentes na indústria de moda. Como se pode constatar, uma delas é a representação gráfica do produto em questão de desenvolvimento e de produção em grande escala.

\section{CONCLUSÃO}

Este trabalho teve como objetivo construir e testar padrões de construção de representação gráfico técnica de produtos do vestuário, portanto um novo procedimento didático que auxilie professor e aluno a criarem condições para o desenvolvimento no processo de ensino e de aprendizagem do desenho técnico. Baseado num 
referencial teórico que procurou abordar conteúdos sobre desenho técnico, normas da ABNT, medidas do corpo humano (baseados em estudos já existentes na ABNT e estudos antropométricos e ergonômicos) e sobre desenho técnicos em diferentes áreas de atuação como arquitetura, engenharias e moda. Assim foi possível entendermos a importância da padronização para que o profissional consiga transmitir nas suas criações articuladas uma linguagem expressiva e original, porém acompanhada da linguagem técnica com detalhes específicos e detalhados.

Portanto, o trabalho só atingiu seus objetivos na medida em que apresentou os processos e métodos pelos quais foi possível construir padrões de representação técnica que satisfizesse os padrões da indústria da moda.

Esta pesquisa na área do desenho de moda exigiu dedicação e criatividade na elaboração de um novo procedimento de padrões para a construção de representação técnica do produto do vestuário, bem como na busca de uma metodologia para sua realização, tendo em vista o pouco tempo do curso de moda em academias e a escassa bibliografia sobre desenho técnico para a área da moda.

Sobre o ponto de vista teórico sentiu-se a necessidade de se ter um embasamento relacionado a normas da ABNT de outras áreas de conhecimento, além de leituras sobre antropomentria e ergomonia, para o aluno, futuro desenhista de moda, poder transformar idéias percebidas e vivenciadas em linguagem visuais e formais, mas também em linguagem técnica. Aqui, se faz necessário ressaltar que a utilização de várias leituras para se expor assuntos que fale sobre normas e padrões dentro do sistema de moda, não teve a intenção de se fazer análise entre as mesmas, nem de confrontar suas fundamentações. Mas para esta pesquisa contribuíram possibilitando desenvolver criticamente e conscientemente o potencial criativo e perceptivo no profissional de desenho de moda. E, a tudo o que diz respeito ao desenho técnico de moda.

Por outro lado foi encontrada uma grande dificuldade na obtenção de conteúdos relacionados aos processos de construção de representação técnica de desenho de moda. Assim, houve a necessidade da elaboração de uma metodologia específica para o desenvolvimento da representação gráfica do desenho técnico, que foi desde a planificação da figura de humana feminina, masculina e infantil até a padronização de linhas de contorno das peças desenhas com modificações na espessura interna do desenho das peças de roupa desenhadas. Esta metodologia foi fun- 
damentada, então, na representação gráfica através de técnicas e procedimentos de outras áreas de conhecimento como a arquitetura e engenharias.

Em segundo lugar sobre o ponto de vista das experimentações práticas, podese dizer que a pesquisa foi realizada através de uma metodologia segundo os preceitos gerais de representatividade gráfica técnica, pelo desenho, representatividade da figura humana planificada e da estrutura de peças de roupas de maneira geral. Para dar conta desses propósitos desenvolveu-se etapa investigativa sobre a estruturação do processo de ensino e de aprendizagem e da pesquisa como um todo. Após a atividade investigativa, criou-se uma metodologia própria onde se trabalhou o uso de padrões seguindo algumas etapas já demonstradas, através das imagens, no corpo deste trabalho.

Na primeira etapa, trabalhou-se o que se resolveu chamar de exercícios básicos para a aprendizagem tais como: o uso de linhas e o uso da figura humana feminina, masculina e infantil planificada, como suporte para os desenhos técnicos. A etapa seguinte foi realizada pela construção gráfica de peças de roupas mais simples como camisetas, partiu-se do entendimento da linha de equilíbrio, de como colocar todas as partes da peças com seus respectivos padrões de identificação.

Foram realizadas inúmeras representações gráficas de peças do vestuário, tanto feminina, como masculinas e infantis e pode-se constatar em síntese que: os procedimentos apresentados permitem que haja uma mudança significativa, tanto na estrutura da forma, como também na expressividade e firmeza do traço do aluno. $E$, que para que haja um melhor aproveitamento por parte de todos os alunos necessitaria de um estudo mais aprofundado sobre antropometria e ergonomia. Constatouse ainda que o uso contrastante das linhas e a padronização de vários elementos do desenho técnico, bem como da figura humana planificada foram os procedimentos que mais possibilitaram trabalhar as particularidades de cada um, mesmo encontrando dificuldades, foi onde se pode explorar a transformação do desenho estético para o desenho técnico. E por último que a utilização das diferentes padronizações técnicas abrem infinitas possibilidades de construções de representações gráficas técnicas dos produtos do vestuário.

Portanto, esta pesquisa torna-se relevante, tanto para educadores, como para os desenhistas de moda, pois é fundamental a conscientização das possibilidades e transformações que se pode realizar através das representações gráficas técnicas e das criações de moda. Acredita-se ser oportuno e relevante a investigação deste 
tema, mediante o estudo das diversas abordagens a investigação que se seguiu e que pode contribuir para maior compreensão do desenvolvimento de padrões de representação gráfica técnica para produtos do vestuário no desenho de moda. Como também no processo educacional esperando que as pessoas somem a estes, novos recursos.

\section{ABSTRACT}

This work synthesizes the research "Drawing Technician: standards of representation for the project of products of clothes", that it had as objective to consider procedures of construction of drawings technician of product of clothes, from the aesthetic drawing. To raise the essential abilities to the graphical representation for development of product project, through bibliographies. To identify to the different clothes products and its specificities and finally, to consider the drawing standardization techniques for graphical representation of clothes products.

Key- Words: Drawing technician, clothes, fashion product.

\section{BIBLIOGRÁFIA}

ABNT. Aplicação de Linhas em Desenhos - Tipos de Linhas - Larguras das Linhas. 1984

Folha de Desenho - Leiaute e Dimensões. 1987

Apresentação da Folha para Desenho Técnico. 1998

Desenho Técnico. 1989

Emprego de Escalas em Desenho Técnico. 1992.

Execução de Caracter para Escrita em Desenho Técnico. 1994

ARAÚJO, Mário. Tecnologia do Vestuário. Lisboa: Fundação Calouste Gulbenkian, 1986

BERTASO, H. de A. Projeto Marketing \& Design de Moda. Porto Alegre. CFP. Senai, 2005

BLONDEAU, C. et al. Mèthode de Dessin Fashion Drawing Method. Paris: Esmod Edition, 1995.

BRANDÃO, Gil. Aprenda a Costurar. Rio de Janeiro: Ediouro (Tecnoprent), 1981.

CASTRO, Carlos Pereira de. Escola de Engenharia Mauá, caderno 4. São Paulo:

Editora Mauá

DAPesquisa, Florianópolis, v.2, n.4, p. 408-422, 2007. 
FRENCH, Thomas Ewing. Desenho Técnico e Tecnologia Gráfica. São Paulo: Globo, 1995.

FULCO, P. de T. \& SILVA, R. L. Modelagem Plana Masculina. Rio de Janeiro:

Senac Nacional, 2003.

JONES, Sue Jenkyn. Diseño de moda. Hong Kong: Blume, 2002

LEITE, ㄹ S. \& VELLOSO,M. D. Desenho técnico de roupa feminina. Rio de Janeiro:

Senac Nacional, 2004.

SCHMITT, A et alii Desenho técnico fundamental. São Paulo: Pedagógica e Universitária, 1977.

SUANO, Celso, PASCHOARELLI, L Carlos. A relação da representação gráfica e da ergonomia: um contexto na moda. In Anpedesign II, Rio de Janeiro, 2006. 